\title{
Convective Structure Changes over the Equatorial Pacific with Highly Increased Precipitation under Global Warming Simulated in the HiRAM
}

\author{
Hien Xuan Bui ${ }^{1}$, Jia-Yuh Yu ${ }^{1}$, Hsiao-Wei Liu ${ }^{2}$, Chia-Ying $\mathrm{Tu}^{3}$, \\ Pin-Ging $\mathrm{Chiu}^{3}$, and Huang-Hsiung $\mathrm{Hsu}^{3}$ \\ ${ }^{1}$ Department of Atmospheric Sciences, National Central University, Taoyuan City, Taiwan \\ ${ }^{2}$ National Center for Disaster Reduction, Taipei, Taiwan \\ ${ }^{3}$ Research Center for Environmental Changes, Academia Sinica, Taipei, Taiwan
}

\begin{abstract}
While most studies have argued a slower increase of $1-3 \% \mathrm{~K}^{-1}$ of precipitation globally, others note that this is not necessarily the case from a regional perspective. In this study, we examine the convective structure changes over the equatorial Pacific with highly increased precipitation under global warming using simulations from the High Resolution Atmospheric Model (HiRAM). The moisture budget analysis shows that the precipitation increases must result from a significant enhancement of convection, with a minor modulation from the thermodynamic effect. Two different types of enhanced convection are identified. Over the mean ascending region, precipitation increases are associated with an enhancement of deep convection; while over the mean descending region, the precipitation increases are a result of enhanced shallow convection.
\end{abstract}

(Citation: Bui, H. X., J.-Y. Yu, H.-W. Liu, C.-Y. Tu, P.-G. Chiu, and H.-H. Hsu, 2019: Convective structure changes over the equatorial Pacific with highly increased precipitation under global warming simulated in the HiRAM. SOLA, 15, 119-124, doi: 10.2151/sola.2019-022.)

\section{Introduction}

Precipitation is an important part of hydrological cycle in the Earth's climate system, hence understanding how future precipitation will change is important because of the profound impacts of precipitation on human activities. Under global warming, increased lower-tropospheric water vapor due to increased surface temperature is significantly larger than the increase rate of precipitation which is about $1-3 \% \mathrm{~K}^{-1}$ globally (Allen and Ingram 2002; Held and Soden 2006; Vecchi and Soden 2007; Wentz et al. 2007). This much slower increase rate in precipitation than in atmospheric water vapor (around $7 \% \mathrm{~K}^{-1}$ ) implies a consequent weakening of the tropical circulation (Held and Soden 2006; Vecchi and Soden 2007). However, the robustness of weakened tropical circulation is not found everywhere in observations and numerical simulations. Both strengthening and weakening of tropical circulation, depending on models and datasets used, are found (Gastineau and Soden 2009; Sohn and Park 2010; Tanaka et al. 2004; Vecchi et al. 2008; Huang 2014), indicating a high degree of regional dependence in tropical precipitation change in response to global warming.

Previous studies have suggested complex changes in precipitation in a warmer climate. For example, Xie et al. (2010) studied changes in precipitation with reanalysis data and climate models for different sea surface temperature (SST) patterns. They found that precipitation changes in future climate are highly sensitive to the pattern of SST warming. The different changes in precipitation

Corresponding author: Jia-Yuh Yu, Department of Atmospheric Sciences, National Central University, Chung-Li, Taoyuan City 32001, Taiwan. E-mail: jiayuh@atm.ncu.edu.tw. are strongly influenced by dry static energy transports into or out of the convective region (Su and Neelin 2003). Chou et al. (2009) studied the mechanism for precipitation changes in different regions and showed the importance of vertical convective structure change. Later, Chen et al. (2016) also found a similar result. More recently, Liu et al. (2018) analyzed the present-day period and the Representative Concentration Pathway 8.5 (RCP8.5) simulations of the Coupled Model Intercomparison Project phase 5 (CMIP5) models in the late 21 st century and they showed that the increase rate of precipitation over the equatorial central and eastern Pacific far exceeds the Clausius-Clapeyron scaling. However, due to the lower spatial resolution in CMIP5 models, they did not address why precipitation increases so drastically over the above region. Motivated by the above studies, this paper further investigates the physical processes leading to highly increased rainfall over the equatorial Pacific based on simulations of the Geophysical Fluid Dynamics Laboratory (GFDL) High Resolution Atmospheric Model (HiRAM).

With a horizontal resolution of approximately $25 \mathrm{~km}$ and the ability in connecting weather forecasts and climate simulations (Voosen 2017), HiRAM allows us to examine in detail the causes for precipitation and circulation changes in a warming world. Previous studies have documented the advantages of using HiRAM to the prediction of seasonal tropical cyclone activity (Chen and Lin 2011; Zhao et al. 2009) and genesis (Camargo et al. 2014), as well as the projection of monsoon precipitation change under global warming (Hsu et al. 2012) from a global-scale point of view. The use of HiRAM is expected to give us a more realistic picture as some recent studies have shown that regional convective structure and precipitation changes could be very sensitive to the model horizontal resolution (Liu et al. 2018; Bui et al. 2019).

\section{Methodology}

\subsection{Model and experiment design}

The HiRAM is a modified version of the GFDL Atmospheric Model version 2.1 (AM2.1). It uses the finite-volume dynamical core on the cubed-sphere grids, with a horizontal resolution of about $0.23^{\circ} \times 0.23^{\circ}$ and 32 model layers (Lin 2004). Designed for global cloud-resolving capability, HiRAM uses a nonintrusive shallow convective scheme (Bretherton et al. 2004) and replaces the deep convective scheme by a six-category bulk cloud microphysics scheme for the resolved component of cumulus convection processes (Zhao et al. 2009). Two time-slice experiments are conducted in this study. The first experiment is an AMIP-like run, forced by observed sea surface temperature (SST) and sea ice concentration (SIC) derived from the Hadley Center sea ice and sea surface temperature dataset (HadISST) for the period from 1979 to 2008 , to represent the present-day climate simulation. The second experiment is forced by SST and SIC obtained from an ensemble mean of all CMIP5 models under the RCP 8.5 scenario for the period from 2075 to 2010 to represent the future warming climate simulation. Here, simulation results from the present-day 
period of 1989-2008 are compared with those from the late $21 \mathrm{st}$ century period of 2081-2100. We also analyze the precipitation changes in the late 21st Century with RCP8.5 scenario from the CMIP5 (Taylor et al. 2012) multi-model mean as a comparison against the HiRAM results (see the supplementary information for details).

\subsection{Moisture and energy budget analysis}

To explore the mechanisms for tropical precipitation changes under global warming, we use the following column integrated moisture anomaly equation (Chou and Neelin 2004; Chou et al. 2009; Chen et al. 2016; Liu et al. 2018):

$$
P^{\prime}=-\left\langle\bar{\omega} \partial_{p} q^{\prime}\right\rangle-\left\langle\omega^{\prime} \partial_{p} \bar{q}\right\rangle-\langle\mathbf{v} \cdot \nabla q\rangle^{\prime}+E^{\prime}+\text { Residual }
$$

where $\overline{()}$ denotes climatology in present climate state and ()$^{\prime}$ represents the difference between future and present climate states. $P$ and $E$ are precipitation and evaporation at the surface, respectively, both in units of energy $\left(\mathrm{W} \mathrm{m}^{-2}\right), \omega$ is pressure velocity, $\mathbf{v}$ is horizontal wind vector, and $q$ is specific humidity also in energy unit by multiplying the specific latent heat $L\left(=2.44 \times 10^{6} \mathrm{~J} \mathrm{~kg}^{-1}\right)$. The angle brackets \langle\rangle denote a mass-weighted integration through the troposphere, i.e., $\langle A\rangle=(1 / g) \int_{p_{T}}^{p_{o}} A d p$, typically from $1000 \mathrm{hPa}$ to the tropopause. In (1), precipitation anomaly $\left(P^{\prime}\right)$ is roughly balanced by a combined contribution from vertical moisture transport anomaly due to moisture stratification change $\left(-\left\langle\bar{\omega} \partial_{p} q^{\prime}\right\rangle\right)$, vertical moisture transport anomaly due to convection change $\left(-\left\langle\omega^{\prime} \partial_{p} \bar{q}\right\rangle\right)$, horizontal moisture transport anomaly $\left(-\langle\mathbf{v} \cdot \nabla q\rangle^{\prime}\right)$, and local evaporation anomaly $\left(E^{\prime}\right)$. The residual term denotes contributions from nonlinear transient eddies, which are generally not part of the physical solution as their magnitudes are much smaller compared to the other terms.

We also examine changes in column integrated vertical moist static energy (MSE) transport, i.e., $\left\langle\omega \partial_{p} h\right\rangle^{\prime}$, to help elucidate the interaction between tropical convection and the surrounding largescale environment. Following Bui et al. (2016), we may further decompose this term into contribution from change in moist static energy $(h)$ and contribution from change in pressure velocity $(\omega)$, respectively, which yields the following approximation:

$$
\left\langle\omega \partial_{p} h\right\rangle^{\prime} \approx\left\langle\bar{\omega} \partial_{p} h^{\prime}\right\rangle+\left\langle\omega^{\prime} \partial_{p} \bar{h}\right\rangle
$$

In (2), $h=q+s$ is the moist static energy (MSE) and $s=T+$ $g z$ is the dry static energy, with $T$ being temperature in energy unit by absorbing the heat capacity at constant pressure $C_{p}=$
$1.005 \mathrm{~kJ} /(\mathrm{kg} \mathrm{K}), g$ the gravity and $z$ the height. A positive value of $\left\langle\omega \partial_{p} h\right\rangle$ indicates an export of column MSE and a stabilization effect for atmosphere, typically associated with the top-heavy deep convection; while a negative value of $\left\langle\omega \partial_{p} h\right\rangle$ indicates an import of column MSE and a destabilization effect for atmosphere, generally linked to the bottom-heavy shallow convection (Back and Bretherton 2006; Bui et al. 2016).

\section{Simulation Results}

\subsection{Precipitation changes}

Figure 1 shows changes of precipitation between the late $21 \mathrm{st}$ Century and the present-day period. Decreased precipitation is found in the western Pacific and ITCZ regions while increased precipitation occurs over the equatorial Pacific and some parts of the Atlantic and Indian oceans. Since positive and negative precipitation anomalies coexist both within the mean ascending and the mean descending regions, the strong cancellations between regional positive and negative anomalies lead to a modest change of precipitation over the entire Tropics. Of particular interest is the marked precipitation increases over the equatorial Pacific $\left(5^{\circ} \mathrm{S}-\right.$ $5^{\circ} \mathrm{N}, 150^{\circ} \mathrm{E}-90^{\circ} \mathrm{W}$ ), with magnitudes from $0.4 \mathrm{~mm}^{-1 a y}{ }^{-1} \mathrm{~K}^{-1}$ to $1.6 \mathrm{~mm}$ day $^{-1} \mathrm{~K}^{-1}$, indicating the greater favorability for convection there under global warming.

From a relative change point of view, Fig. 1b shows the same precipitation pattern but in unit of $\% \mathrm{~K}^{-1}$. An interesting result emerges as the relative change of precipitation over the eastern equatorial Pacific becomes as large as those over the central equatorial Pacific, with a maximum increase rate over $20 \% \mathrm{~K}^{-1}$, much exceeding the Clausius-Clapeyron (CC) scaling of about $7 \% \mathrm{~K}^{-1}$. We note that this pattern is also apparent in CMIP5 multi-model mean results (see Figs. S1a and S1b) although HiRAM simulations are more capable of capturing the details of precipitation changes compared to CMIP5 results. Surprisingly, changes in precipitation closely follow the pattern of tropical SST warming (Fig. 2), with positive precipitation changes occurring over areas of greater SST warming. The above results imply that changes of tropical precipitation under global warming seem to comply better with the "warmer-get-wetter" mechanism rather than the "wetget-wetter" hypothesis, consistent with some previous studies (Xie et al. 2010; Chadwick et al. 2013; Huang 2014).

The causes for marked precipitation changes over the equa-
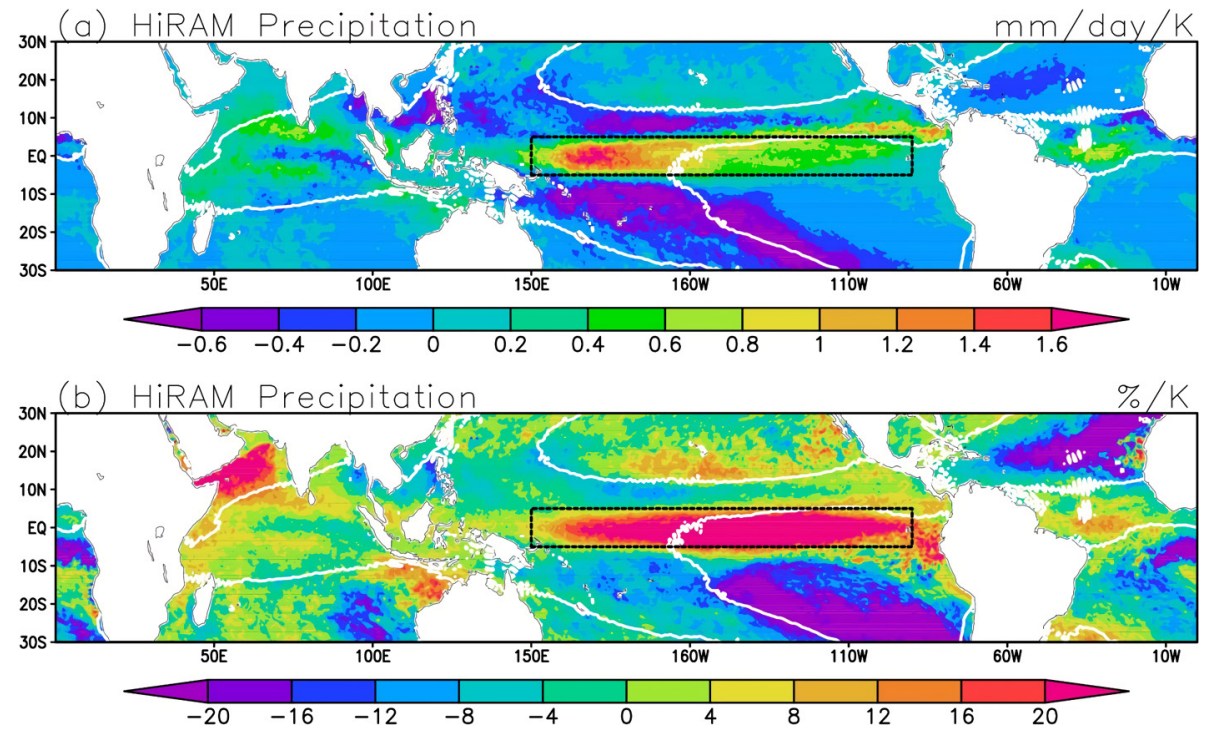

Fig. 1. Precipitation changes in unit of (a) $\mathrm{mm} \mathrm{day}^{-1} \mathrm{~K}^{-1}$ and (b) \% $\mathrm{K}^{-1}$ between the late 21 st Century (2081-2100) and the present-day (1979-2008) simulations. The thick white curves represent the zero contours of climatological mean $500 \mathrm{hPa}$ pressure velocity (average of present-day and global warming simulations). The rectangular box in each panel shows the target domain of equatorial Pacific $\left(5^{\circ} \mathrm{S}-5^{\circ} \mathrm{N}, 150^{\circ} \mathrm{E}-90^{\circ} \mathrm{W}\right)$. Similar results from the CMIP5 multi-model mean are shown in the supplemental information (Fig. S1). 


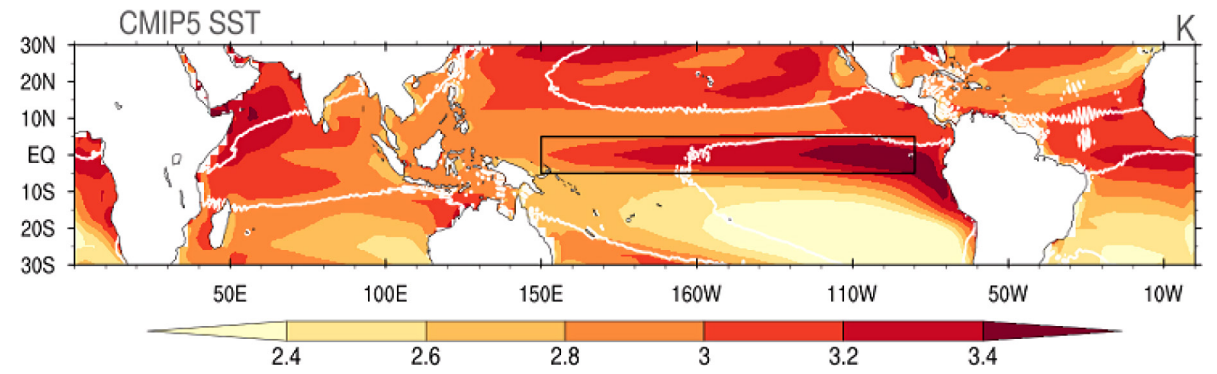

Fig. 2. Same as Fig. 1, but showing SST changes between the late 21st century (2081-2100) and the present-day period (1979-2008).

Table 1. Moisture budget results for all terms in equation (1) averaged over the equatorial Pacific domain $\left(5^{\circ} \mathrm{S}-5^{\circ} \mathrm{N}, 150^{\circ} \mathrm{E}-90^{\circ} \mathrm{W}\right)$, the mean ascending only $\left(5^{\circ} \mathrm{S}-5^{\circ} \mathrm{N}, 150^{\circ} \mathrm{E}-160^{\circ} \mathrm{W}\right)$ and the mean descending only $\left(5^{\circ} \mathrm{S}-5^{\circ} \mathrm{N}, 160^{\circ} \mathrm{W}-90^{\circ} \mathrm{W}\right)$ regions of the equatorial Pacific, respectively. Budget results for terms in equation (2) and changes in the normalized "gross moist stability" $\left(G M S^{\prime}\right)$ are also displayed below for discussion purpose. All terms are in units of $\mathrm{W} \mathrm{m}^{-2}$. As background information, the numbers in parentheses show the climatological means (average between the RCP8.5 warming and historical climate simulations) for all terms.

\begin{tabular}{llll}
\hline \multicolumn{1}{c}{ Terms } & \multicolumn{1}{c}{ Total } & \multicolumn{1}{c}{ Ascending } & \multicolumn{1}{c}{ Descending } \\
\hline$P^{\prime}$ & $65.19(132.77)$ & $79.48(210.06)$ & $50.91(77.79)$ \\
$-\left\langle\omega \partial_{p} q\right\rangle^{\prime}$ & $68.22(27.08)$ & $86.10(118.63)$ & $55.50(-38.04)$ \\
$-\left\langle\omega^{\prime} \partial_{p} \bar{q}\right\rangle$ & 63.78 & 63.24 & 64.16 \\
$-\left\langle\bar{\omega} \partial_{p} q^{\prime}\right\rangle$ & 4.44 & 22.85 & -8.67 \\
$-\langle\mathbf{v} \cdot \nabla q\rangle^{\prime}$ & $-6.16(-14.45)$ & $-4.42(-36.75)$ & $-7.40(1.41)$ \\
$E^{\prime}$ & $6.07(117.19)$ & $1.83(127.59)$ & $9.08(109.79)$ \\
Residual & $-2.93(2.95)$ & $-4.03(0.59)$ & $-6.27(4.63)$ \\
\hline$\left\langle\omega \partial_{p} h\right\rangle^{\prime}$ & $-0.914(-2.97)$ & $1.07(6.11)$ & $-2.32(-9.43)$ \\
$\left\langle\bar{\omega} \partial_{p} h^{\prime}\right\rangle$ & 0.66 & -3.68 & 3.74 \\
$\left\langle\omega^{\prime} \partial_{p} \bar{h}\right\rangle$ & -1.57 & 4.74 & -6.06 \\
$G M S^{\prime}$ & -0.014 & 0.013 & -0.046 \\
\hline
\end{tabular}

torial Pacific can be quantitatively measured using the moisture budget analysis over the mean ascending and the mean descending regions separately (see Table 1). As shown, the vertical moisture transport anomaly due to significant convection enhancement, $-\left\langle\omega^{\prime} \partial_{p} \bar{q}\right\rangle \gg 0$ (i.e., dynamic effect), dictates the precipitation increases, with comparable sizes in the mean ascending and the mean descending regions (63.24 vs. $\left.64.16 \mathrm{~W} \mathrm{~m}^{-2}\right)$. In contrast, the vertical moisture transport anomaly due to moisture change, $-\left\langle\bar{\omega} \partial_{p} q^{\prime}\right\rangle$ (i.e., thermodynamic effect), appears to play only a modulating role, with a sizable positive contribution in the mean ascending region and a minor negative contribution in the mean descending region $\left(22.85\right.$ vs. $\left.-8.67 \mathrm{~W} \mathrm{~m}^{-2}\right)$, which is consistent with the so-called "wet-get-wetter, dry-get-drier" mechanism. The change in horizontal advection, $-\langle\mathbf{v} \cdot \nabla q\rangle^{\prime}$, is always negative due to enhanced dry and cold advection into the convective centers. Although change in the local evaporation term $E^{\prime}$ is always positive, its contribution in supporting positive precipitation anomalies is modest both in the mean ascending and the mean descending regions $\left(1.83\right.$ vs. $\left.9.08 \mathrm{~W} \mathrm{~m}^{-2}\right)$. The residual term is small and negative in both regions. In summary, the positive precipitation changes over the equatorial Pacific are mostly a result of the enhanced convection (i.e., dictated by the dynamic effect via $-\left\langle\omega^{\prime} \partial_{p} \bar{q}\right\rangle$ term).

Next, we analyze changes in vertical MSE transport to understand the implications of convective structure change (see the last 3 rows of Table 1). As shown, $\left\langle\omega \partial_{p} h\right\rangle^{\prime}$ is positive in the mean ascending region and negative in the mean descending region, implying a stabilized atmosphere in the former and a destabilized atmosphere in the latter. If we further decompose the vertical MSE transport as in (2), the term due to change in MSE profile, $\left\langle\bar{\omega} \partial_{p} h^{\prime}\right\rangle$ (i.e., thermodynamic effect), shows nearly equal but opposite trends between the mean ascending and the mean descending regions $\left(-3.67\right.$ vs. $\left.3.74 \mathrm{~W} \mathrm{~m}^{-2}\right)$. The negative (positive) value of $\left\langle\bar{\omega} \partial_{p} h^{\prime}\right\rangle$ within the mean descending (ascending) region implies an import (export) of column MSE. However, as shown in Table 1 , the sign of $\left\langle\omega \partial_{p} h\right\rangle^{\prime}$ is determined by the term due to change in convection, $\left\langle\omega^{\prime} \partial_{p} h\right\rangle$ (i.e., dynamic effect) as its amplitude is always greater than $\left\langle\bar{\omega} \partial_{p} h^{\prime}\right\rangle$ both in the mean ascending and the mean descending regions (4.74 vs. $-6.06 \mathrm{~W} \mathrm{~m}^{-2}$ ).

At first glance, positive $\left\langle\omega^{\prime} \partial_{p} \bar{h}\right\rangle$ in the mean ascending region and negative $\left\langle\omega^{\prime} \partial_{p} \bar{h}\right\rangle$ in the mean descending region seem to point to an opposite trend in convection change between the two regions, which is in contradiction to the results shown in moisture budget that have suggested the enhancement of convection in both regions. Because the sign of vertical MSE transport is sensitive to the structure of convection (Back and Bretherton 2006; Bui et al. 2016), we speculate that the enhanced convection may have very different structures between the mean ascending and the mean descending regions.

\subsection{Convective structure changes}

Figures $3 \mathrm{a}$ and $3 \mathrm{c}$ show the longitude-height cross sections of the climatological "apparent heat source" $Q_{1}$ and "apparent moisture sink" $Q_{2}$ (Yanai and Johnson 1993) along the equator. To the west of dateline (within ITCZ), large values of $Q_{1}$ occur between 600 and $400 \mathrm{hPa}$ (Fig. 3a), accompanied by large values of $Q_{2}$ over the same locations (Fig. 3c), indicating the dominance of deep convection. To the east of dateline (outside ITCZ), $Q_{1}$ and $Q_{2}$ are mostly negative throughout the troposphere, showing the suppression of convection by subsidence motions. Under global warming, large positive $Q_{1}$ and $Q_{2}$ anomalies occur in the upper troposphere west of $170^{\circ} \mathrm{W}$, showing the enhancement of deep convection. In contrast, strong positive $Q_{1}$ and $Q_{2}$ anomalies are confined in the lower troposphere east of $170^{\circ} \mathrm{W}$, indicating the enhancement of shallow convection (Figs. $3 \mathrm{~b}$ and $3 \mathrm{~d}$ ).

The vertical structure of pressure velocity (omega) changes between the late 21 st Century and the present-day periods are shown in Fig. 4. The deep (top-heavy) convection increases over the mean ascending region with a peak at around $400 \mathrm{hPa}$, indicating the deepening of convection under global warming; while the shallow (bottom-heavy) convection increases over the mean descending region with a peak at around $850 \mathrm{hPa}$, both concurring with the results shown in Figs. $3 b$ and $3 d$. In summary, two different types of enhanced convection are identified over the equatorial Pacific under global warming. In the mean ascending region, the increased rainfall is due to the enhanced deep convection; while in the mean descending region, the increased rainfall is due to the enhancement of shallow convection. The enhanced upward motions in both regions must be accompanied by enhanced downward motions elsewhere in a much larger spatial scale, which on average also implies the weakening of tropical circulation.

Finally, we attempt to associate the increased precipitation over the equatorial Pacific with changes in liquid water path (LWP) and ice water path (IWP) in Fig. 5. Over the equatorial Pacific, LWP increases from 0.005 to $0.02 \mathrm{~kg} \mathrm{~m}^{-2}$, with larger values over the mean descending region (east of the dateline); while IWP 

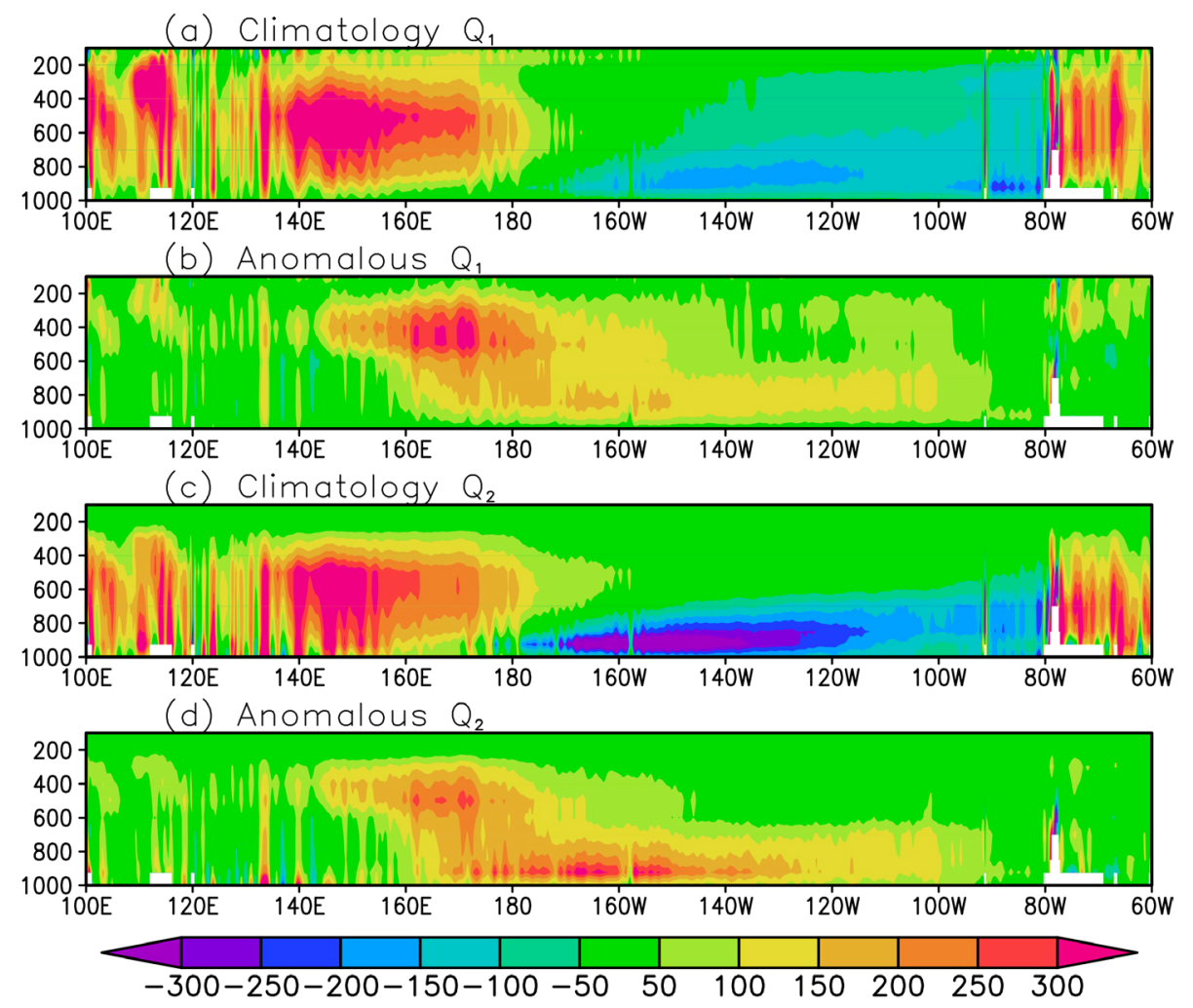

Fig. 3. Longitude-height cross sections along the equator of the (a,b) apparent heat source $Q_{1}$ and (c, d) apparent moisture sink $Q_{2}$ for the climatological mean and difference between the late 21 st Century and the present-day simulations. Units are $\mathrm{W} \mathrm{kg}^{-1}$.

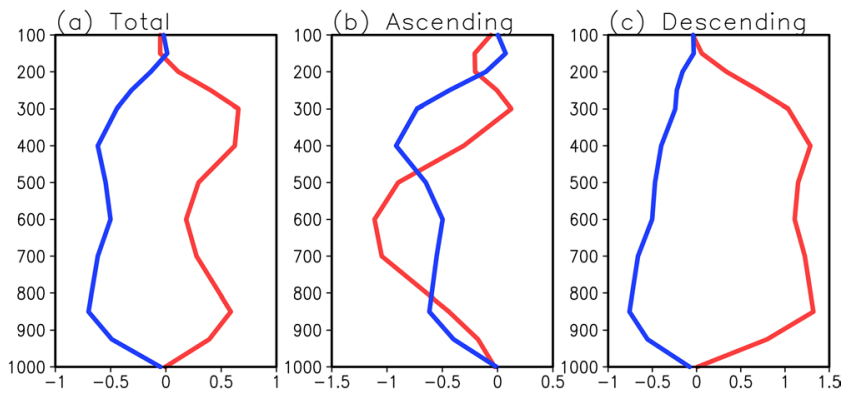

Fig. 4. Vertical profile of the mean (red) and anomalous (blue) vertical velocity averaged over the (a) equatorial Pacific domain $\left(5^{\circ} \mathrm{S}-5^{\circ} \mathrm{N}\right.$, $\left.150^{\circ} \mathrm{E}-90^{\circ} \mathrm{W}\right)$, (b) mean ascending only $\left(5^{\circ} \mathrm{S}-5^{\circ} \mathrm{N}, 150^{\circ} \mathrm{E}-160^{\circ} \mathrm{W}\right)$ and (c) mean descending only $\left(5^{\circ} \mathrm{S}-5^{\circ} \mathrm{N}, 160^{\circ} \mathrm{W}-90^{\circ} \mathrm{W}\right)$ regions of the equatorial Pacific, respectively. The unit is $10^{-2} \mathrm{~Pa} \mathrm{~s}^{-1}$.

increases mostly over the mean ascending region (west of the dateline), with smaller values over the mean descending region, consistent with the convective structure changes shown in Figs. 3 and 4.

We note that the above enhancement of convection may change the radiation balance of atmosphere through various competing effects. On the one hand, the enhanced convection produces a cooling effect through upward reflection of shortwave (also known as the "albedo effect"). On the other hand, the enhanced convection also contributes to a warming effect through downward longwave radiation emitted from clouds (also known as the "greenhouse effect"). To what extent do the two effects compete with each other is another interesting topic worthy of investigation. Since such an investigation requires a lengthy discussion of the cloud radiative effect, we will put it in our future work.

\section{Concluding remarks}

In this study, convective structure changes over the equatorial Pacific $\left(5^{\circ} \mathrm{S}-5^{\circ} \mathrm{N}, 150^{\circ} \mathrm{E}-90^{\circ} \mathrm{W}\right)$ with highly increased precipitation rates $\left(>20 \% \mathrm{~K}^{-1}\right)$ under global warming are examined based on simulations from the Hi-Resolution Atmospheric Model (HiRAM). Major findings are summarized as follow:

(i) HiRAM projects a marked increase in precipitation rate ( $>$ $20 \% \mathrm{~K}^{-1}$ ) over the equatorial Pacific (Fig. 1) with a pattern very similar to the SST warming, which is in general consistent with the CMIP5 multi-model mean results (see Fig. S1 in the supplement materials).

(ii) The above precipitation increases come from a notable enhancement of convection (i.e., $-\left\langle\omega^{\prime} \partial_{p} \bar{q}\right\rangle \gg 0$, the dynamic effect), with a minor modulating effect from the thermodynamic effect (i.e., $-\left\langle\bar{\omega} \partial_{p} q^{\prime}\right\rangle>0$ over the mean ascending region and $-\left\langle\bar{\omega} \partial_{p} q^{\prime}\right\rangle<0$ over the mean descending region). Contributions from horizontal moisture advection and local evaporation are too small to account for the simulated precipitation changes (Table 1).

(iii) Over the mean ascending region $\left(5^{\circ} \mathrm{S}-5^{\circ} \mathrm{N}, 150^{\circ} \mathrm{E}-160^{\circ} \mathrm{W}\right)$, the precipitation increases are associated with an enhancement of deep convection; while over the mean descending region $\left(5^{\circ} \mathrm{S}-5^{\circ} \mathrm{N}, 160^{\circ} \mathrm{W}-90^{\circ} \mathrm{W}\right)$, the precipitation increases are a result of enhanced shallow convection (Figs. 3, 4 and 5). Finally, the very different convective structure changes between the mean ascending and mean descending regions also imply a different response in "gross moist stability" (GMS) changes (Yu et al. 1998; Raymond et al. 2009). As shown in Table 1, GMS tends to increase over the mean ascending region due to enhanced deep convection but decrease over the mean descending region due to more shallow convection (Bui et al. 2016), resulting in a more stable environment and weakening of circulation over the former and a less stable environment and strengthening of circulation over the latter (Chou and Chen 2010; Chen et al. 2016). 

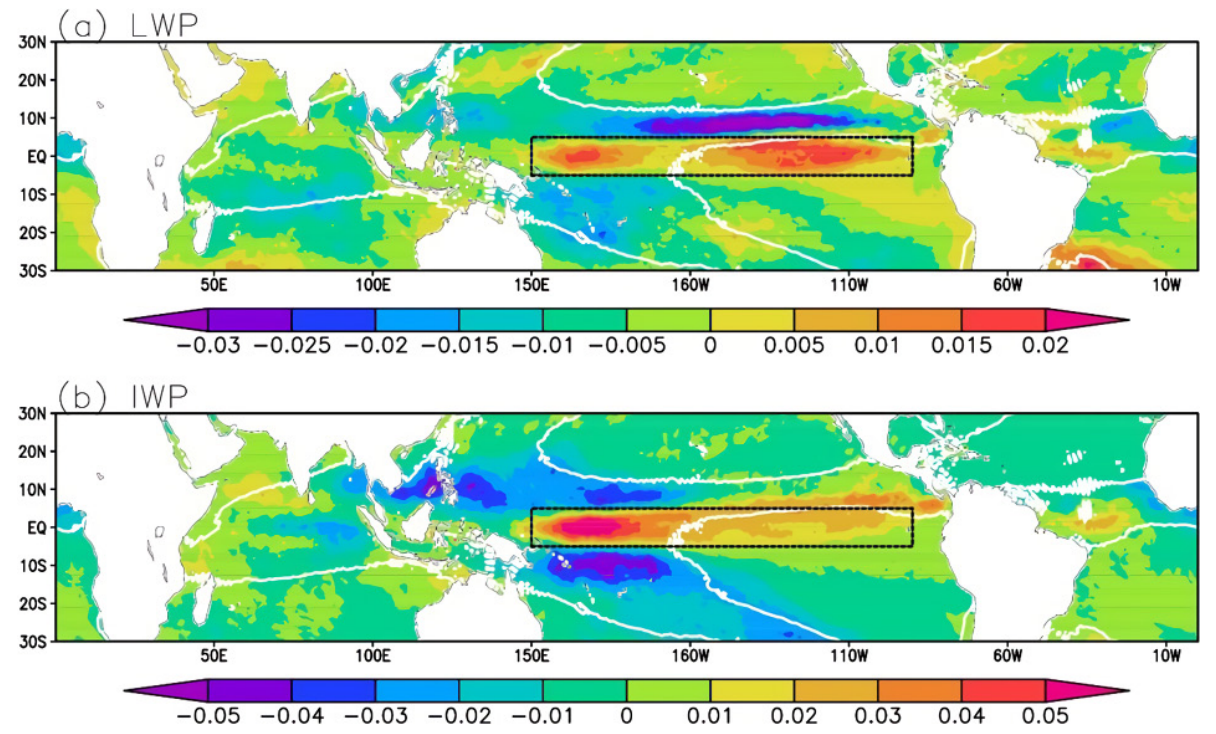

Fig. 5. Same as Fig. 1, but for differences in the (a) liquid water path $\left(\mathrm{kg} \mathrm{m}^{-2}\right)$ and (b) ice water path $\left(\mathrm{kg} \mathrm{m}^{-2}\right)$ in the late 21 st Century relative to the present-day simulations.

Although we've demonstrated two types of convective structure changes over the equatorial Pacific under global warming, some caveats apply to the results presented here. First, we use SST projected from CMIP5 models as the boundary condition for the future warming climate simulation. Because most climate models in CMIP3 and CMIP5 tend to generate an excessive westward extension (i.e., cold bias) of the equatorial Pacific cold tongue ( $\mathrm{Li}$ and Xie 2012; Li and Xie 2014; Li et al. 2016), the amplitudes of atmospheric response over the equatorial Pacific might be underestimated, though the results should be qualitatively similar. Second, while HiRAM is designed to be a "cloud-resolving capable" global model, the $25 \mathrm{~km}$ resolution used in this study is not enough for cloud-resolving simulations. Besides, the above findings are based on atmospheric model simulations forced by prescribe SST (i.e., AMIP-like runs). More works are required to elucidate the different roles played by deep and shallow convection and the impacts of changing GMS on precipitation and circulation changes under global warming using the cloud-resolving model or the high-resolution coupled model results.

\section{Acknowledgments}

This research was supported by the Ministry of Science and Technology (MOST) in Taiwan under Grant MOST105-2111-M008-025-MY3. The first author (H. X. Bui) was also sponsored by the MOST Postdoctoral Fellowship under Grant MOST106-2811M-008-003. The HiRAM simulations were conducted and archived at the Research Center for Environmental Changes (RCEC), Academia Sinica in Taiwan. The authors sincerely thank the two anonymous reviewers for their very helpful comments to improve the quality of this manuscript.

\section{Supplement description}

Supplement material attached to this manuscript describes the results from the CMIP5 multi-model mean as a comparison against the HiRAM simulations.

Edited by: Y. Takaya

\section{References}

Allen, M. R., and W. J. Ingram, 2002: Constraints on future changes in climate and the hydrologic cycle. Nature, 419, 224-232.

Back, L. E., and C. S. Bretherton, 2006: Geographic variability in the export of moist static energy and vertical motion profiles in the tropical Pacific. Geophys. Res. Lett., 33, L17810, doi: 10.1029/2006GL026672.

Bretherton, C. S., J. R. McCaa, and H. Grenier, 2004: A new parameterization for shallow cumulus convection and its application to marine subtropical cloud-topped boundary layers. Part I: Description and 1D results. Mon. Wea. Rev., 132, 864-882, doi:10.1175/1520-0493(2004)132.

Bui, H. X., J.-Y. Yu, and C. Chou, 2016: Impacts of vertical structure of large-scale vertical motion in tropical climate: Moist static energy framework. J. Atmos. Sci., 73, 4427-4437, doi:10.1175/JAS-D-16-0031.1.

Bui, H. X., J.-Y. Yu, and C. Chou, 2019: Impacts of model spatial resolution on the vertical structure of convection in the Tropics. Climate Dyn., 52, 15-27, doi:10.1007/s00382-0184125-3.

Camargo, S. J., M. K. Tippett, A. H. Sobel, G. A. Vecchi, and M. Zhao, 2014: Testing the performance of tropical cyclone genesis indices in future climates using the HiRAM model. J. Climate, 27, 9171-9196, doi:10.1175/JCLI-D-13-00505.1.

Chadwick, R., I. Boutle, and G. Martin, 2013: Spatial patterns of precipitation changes in CMIP5: Why the rich do not get richer in the Tropics. J. Climate, 26, 3803-3822, doi: 10.1175/JCLI-D-12-00543.1.

Chen, J.-H., and S.-J. Lin, 2011: The remarkable predictability of inter-annual variability of Atlantic hurricanes during the past decade. Geophys. Res. Lett., 38, L11804, doi:10.1029/ 2011 GL047629.

Chen, C.-A., J.-Y. Yu, and C. Chou, 2016: Impacts of vertical structure of convection in global warming: The role of shallow convection. J. Climate, 29, 4665-4684, doi:10.1175/ JCLI-D-15-0563.1.

Chou, C., and J. D. Neelin, 2004: Mechanisms of global warming impacts on regional tropical precipitation. J. Climate, 17, 2688-2701.

Chou, C., J. D. Neelin, C.-A. Chen, and J.-Y. Tu, 2009: Evaluating the rich-get-richer mechanism in tropical precipitation change under global warming. J. Climate, 22, 1982-2005, 
doi:10.1175/2008JCLI2471.1.

Chou, C., and C.-A. Chen, 2010: Depth of convection and the weakening of tropical circulation in global warming. $J$. Climate, 23, 3019-3030.

Gastineau, G., and B. J. Soden, 2009: Model projected changes of extreme wind events in response to global warming. Geophys. Res. Lett., 36, L10810, doi:10.1029/2009GL037500.

Held, I. M., and B. J. Soden, 2006: Robust responses of the hydrological cycle to global warming. J. Climate, 19, 5686-5699, doi:10.1175/JCLI3990.1.

Hsu, P.-C., T. Li, J.-J. Luo, H. Murakami, A. Kitoh, and M. Zhao, 2012: Increase of global monsoon area and precipitation under global warming: A robust signal? Geophys. Res. Lett., 39, L06701, doi:10.1029/2012GL051037.

Huang, P., 2014: Regional response of annual-mean tropical rainfall to global warming. Atmos. Sci. Lett., 15, 103-109, doi: $10.1002 /$ asl2.475.

Li, G., and S.-P. Xie, 2012: Origins of tropical-wide SST biases in CMIP multi-model ensembles. Geophys. Res. Lett., 39, L22703, doi:10.1029/2012GL053777.

Li, G., and S.-P. Xie, 2014: Tropical biases in CMIP5 multimodel ensemble: The excessive equatorial Pacific cold tongue and double ITCZ problems. J. Climate, 27, 1765-1780, doi: 10.1175/JCLI-D-13-00337.1.

Li, J.-L., W.-L. Lee, T. Lee, E. Fetzer, J.-Y. Yu, T. L. Kubar, and C. Boening, 2015: The impacts of cloud snow radiative effects on Pacific Ocean surface heat fluxes, surface wind stress, and ocean temperatures in coupled GCM simulations. J. Geophys. Res. Atmos., 120, 2242-2260, doi:10.1002/2014JD 022538 .

Lin, S.-J., 2004: A "vertically Lagrangian" finite-volume dynamical core for global models. Mon. Wea. Rev., 132, 22932307.

Liu, H.-W., J.-Y. Yu, and C.-A. Chen, 2018: Changes of tropical precipitation and convective structure under global warming projected by CMIP5 model simulations. Terr. Atmos. Ocean. Sci., 29, 429-440, doi:10.3319/TAO.2017.09.27.01.

Raymond, D. J., S. Sessions, A. Sobel, and Z. Fuchs, 2009: The mechanics of gross moist stability. J. Adv. Model. Earth Sys., 1, 9, doi:10.3894/JAMES.2009.1.9.

Sohn, B. J., and S.-C. Park, 2010: Strengthened tropical circulations in past three decades inferred from water vapor trans- port. J. Geophys. Res., 115, D15112, doi:10.1029/2009JD 013713.

Su, H., and J. D. Neelin, 2003: The scatter in tropical average precipitation anomalies. J. Climate, 16, 3966-3977, doi: 10.1175/1520-0442(2003)016<3966:TSITAP >2.0.CO;2.

Tanaka, H. L., N. Ishizaki, and A. Kitoh, 2004: Trend and interannual variability of Walker, monsoon and Hadley circulations defined by velocity potential in the upper troposphere. Tellus $A$, 56, 250-269, doi:10.1111/j.1600-0870.2004.00049.x.

Taylor, K. E., R. J. Stouffer, and G. A. Meehl, 2012: An overview of CMIP5 and the experiment design. Bull. Amer. Meteor. Soc., 93, 485-498, doi:10.1175/BAMS-D-11-00094.1.

Vecchi, G. A., and B. J. Soden, 2007: Global warming and the weakening of the tropical circulation. J. Climate, 20, 43164340, doi:10.1175/JCLI4258.1.

Vecchi, G. A., A. Clement, and B. J. Soden, 2008: Examining the tropical Pacific's response to global warming. EOS, Tran. Amer. Geophy. Union, 89, 81, doi:10.1029/2008EO090002.

Voosen, P., 2017: The weather master. Science, 356, 128-131, doi:10.1126/science.356.6334.128.

Wentz, F. J., L. Ricciardulli, K. Hilburn, and C. Mears, 2007: How much more rain will global warming bring? Science, 317, 233-235, doi:10.1126/science.1140746.

Xie, S.-P., C. Deser, G. A. Vecchi, J. Ma, H. Teng, and A. T. Wittenberg, 2010: Global warming pattern formation: sea surface temperature and rainfall. J. Climate, 23, 966-986.

Yanai, M., and R. H. Johnson, 1993: Impacts of cumulus convection on thermodynamic fields. Meteor. Monogr., 46, Amer. Meteor. Soc., 39-62, doi:10.1007/978-1-935704-13-3-4.

Yu, J.-Y., C. Chou, and J. D. Neelin, 1998: Estimating the gross moist stability of the tropical atmosphere. J. Atmos. Sci., 55, 1354-1372, doi:10.1175/1520-0469(1998)055<1354: ETGMSO $>2.0$.CO;2.

Zhao, M., I. M. Held, S.-J. Lin, and G. A. Vecchi, 2009: Simulations of global hurricane climatology, interannual variability, and response to global warming using a $50-\mathrm{km}$ resolution GCM. J. Climate, 22, 6653-6678, doi:10.1175/2009JCLI 3049.

Manuscript received 4 December 2018, accepted 17 April 2019

SOLA: https://www.jstage.jst.go.jp/browse/sola/ 